\title{
Dietary nitrate from beetroot juice selectively reduces central blood pressure in type 2 diabetes: the randomized, controlled VaSera trial
}

\author{
C.E. Mills ${ }^{1}$, V. Govoni ${ }^{1}$, L. Faconti ${ }^{1}$, M.L. Casagrande ${ }^{1}$, P. Maskell ${ }^{2}$, A. Masani ${ }^{2}$, \\ H. Crickmore ${ }^{1}$, F. Iqbal ${ }^{1}$, S. Morant ${ }^{3}$, A.J. Webb ${ }^{2}$ and J.K. Cruickshank ${ }^{1}$ \\ ${ }^{1}$ Diet and Cardiometabolic Health Research Group and, \\ ${ }^{2}$ British Heart Foundation Cardiovascular Division, Faculty of Life Sciences \& Medicine, King's College London, \\ SE1 $9 N H$ and \\ ${ }^{3}$ Medicines Monitoring Unit (MEMO), University of Dundee, DD1 4HN
}

Dietary nitrate reduces peripheral blood pressure $(\mathrm{BP})^{(1)}$ and arterial stiffness $(\mathrm{AS})^{(2)}$ in healthy people via the nitrate-nitrite-nitric oxide pathway; effects in unhealthy populations are less clear. Although acute studies are plentiful, chronic effects of dietary nitrate are scarce, with the longest trial to our knowledge lasting 4 weeks $^{(3)}$.

Type 2 diabetes (T2D) is characterized by cardiac and vascular disease even before formal diagnosis ${ }^{(4)}$. AS measured as aortic pulse wave velocity (PWV) is a powerful index of cardiovascular and all-cause mortality, crucially independent of BP, in people with or at risk of T2D ${ }^{(5)}$. We tested if nitrate in beetroot juice would reduce AS independently of change in BP in patients with or at risk of T2D. (This study is part of a factorial trial also testing diuretic, spironolactone; here we only present results of the dietary nitrate versus placebo arm).

126 patients were randomised, double-blind to active (nitrate containing) or placebo (nitrate free) beetroot juice ( $\leq 11$ or $0 \mathrm{mmol}$ ) daily over 24 weeks in a parallel design. AS was measured by nominally BP independent cardio-ankle vascular index (CAVI) and as aortic PWV; BP and other haemodynamic parameters were also measured. Heart structure and function were assessed in a subgroup $(\mathrm{n}=87)$ by $2 \mathrm{D}$ ultrasound. Intention-to-treat analysis was performed, adjusting for $\mathrm{BP}$ where appropriate.

There were no differences between the active and placebo beetroot juices in change in peripheral systolic or diastolic BP, nor in change in AS measured as CAVI or aortic PWV ( $p=0 \cdot 8,0 \cdot 9,1.0$ and 0.8 respectively). However, plasma nitrate and nitrite concentrations did increase 4 - and 2 -fold respectively $(\mathrm{p}<0.001$ and $=0.02$ ), suggesting the nitrate-nitrite-nitric oxide pathway was not interrupted. This was simultaneous to a decrease in central systolic $\mathrm{BP}$ on nitrate-containing juice versus placebo (mean $[95 \% \mathrm{CI}] ;-2 \cdot 6[-4 \cdot 5,-0 \cdot 8] \mathrm{mmHg}$, $\mathrm{p}=0.007$ ), consistent with our previous findings of normoxia-dependent conduit artery dilatation after inorganic nitrite, selectively reducing central systolic $\mathrm{BP}^{\left({ }^{(6)}\right.}$.

Dietary nitrate also decreased left ventricular end diastolic and systolic volume $(-6.3[-11 \cdot 1,-1 \cdot 6] \mathrm{mL}$ and $-3 \cdot 2[-5.9,-0.5] \mathrm{mL}$, $\mathrm{p}<0.05)$ and increased end diastolic mass/volume ratio $(0.04[0,0.7] \mathrm{g} / \mathrm{mL}, \mathrm{p}<0.05)$ versus placebo, which are beneficial cardiac changes. There were no drug-juice interactions.

Despite not reducing arterial stiffness independently of BP change, dietary nitrate selective reduced central BP which may have greater impact than just peripheral BP for managing cardiac and vascular risk ${ }^{(7)}$.

1. Siervo M, Lara J, Ogbonmawan I et al. (2013) J Nutr 143, 818-286.

2. Ghosh S, Kapil V, Fuentes-Calvo I et al. (2013) Hypertension 61, 1091-1102.

3. Kapil V, Khambata RS, Robertson A, Caulfield et al. (2014) Hypertens 65, 320-327.

4. Selvin E, Steffes MW, Zhu H et al. (2010) $N$ Engl J of Med 362, 800-811.

5. Cruickshank JK, Riste L, Anderson SG et al. (2002) Circulation 106, 2085-2090.

6. Omar SA, Fok H, Tilgner KD et al. (2015) 131, 381-389.

7. McEniery CM, Yasmin, McDonnell B et al. (2008) Hypertension 51, 1476-1482. 